\title{
THE EFFECT OF EGG SHELL VERSUS FLUORIDE VARNISH ON REMINERALIZATION OF EARLY ENAMEL DEMINERALIZED LESIONS
}

\author{
Hala M. Fares *, Muhammad A Samman** and Ola Barakat***
}

\begin{abstract}
Twenty freshly extracted non-carious human molars were used. The mineral content of all teeth was initially assessed using EDX. Teeth were then divided randomly into two groups each containing ten samples. All teeth were placed in demineralizing agent after which one group (I) was remineralized using egg shell solution while the other group (II) was remineralized using fluoride varnish (Proshield, President dental Germany). This process was held in a $\mathrm{pH}$ cycling mode.Regarding mineral content specimens of both groups were initially assessed (base line measurements), then reassessed directly after demineralization, three days from remineralization and the end of seven days remineralization period. Results were as follow : Regarding Ca wt \% and comparing the two groups there was no statistical significance at base line measurements, after demineralization and after three days from remineralization. Meanwhile after seven days remineralization group (I) demonstrated statistically significant lower mean Ca atomic wt \% than group (II). Regarding phosphorus atomic wt $\%$ for measurements of base line, after demineralization and after remineralization there was no statistical significance between the two groups. Regarding the effect of time for Ca wt \% and after seven days group (I) showed non statistically significant decrease in Ca wt \% compared to that at base line, while group (II) showed non statistically significant difference from the value measured at base line. For the $\mathrm{P}$ wt $\%$ and after seven days both groups demonstrated non statistically significant lower mean values compared to base line data.
\end{abstract}

\section{Key words Remineralization - egg shell - fluoride varnish Introduction}

\section{INTRODUCTION}

Dental caries is considered to be the most common chronic disease ${ }^{(1)}$. Restorations of carious lesions by tooth cutting procedures then application of restorative material is a repetitive and irreversible procedural cycle which eventually increases the size of restoration and ends up by further loss of tooth structure with time ${ }^{(2)}$. So it would seem

* Associate Professor, Department of Operative Dentistry, Faculty of Oral and Dental Surgery, Misr University for Science and Technology. Egypt.

** Associate Professor, Dental Biomaterials, Faculty of Dental Medicine, Al Azhar University Cairo, Egypt

*** Associate Professor, Operative Dentistry, Faculty of Oral and Dental Surgery, Misr University for Science and Technology, Cairo, Egypt 
most appropriate to concentrate on monitoring and managing lesions in the subclinical stage. The early enamel demineralization occurs as a result of lowering in the $\mathrm{pH}$ level at the tooth surface due to the production of acids by cariogenic bacteria ${ }^{(3)}$. This early enamel demineralization is a reversible process including alternating periods of de-and remineralization. Under optimal conditions, the number of episodes of remineralization exceed the number of episodes of demineralization, and caries is arrested $^{(4)}$. Fluorides are powerful effective remineralizing agents ${ }^{(5,6)}$. Egg shell has recently been described as a rich source of minerals containing calcium, phosphorus, magnesium and strontium ${ }^{(2,3)}$. Egg shell being a rich source of calcium , contains 94\% calcium carbonate, $1 \%$ calcium phosphate, $1 \%$ magnesium carbonate and $4 \%$ organic matter ${ }^{(7)}$. Reports of two separate animal and human studies included the use of egg shell as a bone substitute for treatment of maxillofacial defects. The results showed that egg shell was biocompatible, safe, of comparatively lower cost and,most important, could be used as an alternative to bone grafts for regeneration of bone defects ${ }^{(8,9)}$. Other studies stated that egg shell had antirachitic effect due to the fact that it stimulates chondrocyte differentiation and cartilage growth, making it a positive factor for treatment of osteoporosis $^{(10,11)}$. In this study, the point of view was to assess the effect of egg shell on remineralization of early enamel demineralized lesions and compare it to the effect of fluoride which is known as a powerful remineralizing agent. The null hypothesis is to prove that egg shell has the same potent remineralizing effect as fluoride.

\section{MATERIALS AND METHODS}

\section{Specimens preparation}

Twenty freshly extracted, intact human molars were used in this study. The teeth belonged to patients at the age range of 30-50 yrs. old and were extracted for periodontal reasons. Teeth were col- lected from patients at the dental clinics of the College of Oral and Dental Surgery, Misr University for Science and Technology. All teeth were stored in deionized water until use. Before usage the teeth were thoroughly cleaned ultrasonically. The external enamel surface of all teeth was polished using rotary discs and silicon carbide abrasive papers. The mineral content of all teeth was assessed quantitatively (base line measurements) using EDX.

The Scanning Electron Microscope for ... samples. Using SEM Model Quanta 250 FEG (Field Emission Gun) attached with EDX Unit (Energy Dispersive X-ray Analyses), with accelerating voltage $30 \mathrm{~K} . V$. , magnification $14 x$ up to 1000000 and resolution for Gun.1n).FEI company, Netherlands

\section{Grouping of samples}

The teeth were divided into two groups, (each containing ten samples) as follow :

Group (I) ( $\mathrm{n}=10)$ : Intended to be demineralized and then remineralized using prepared egg shell solution.

Group (II) (n=10) : Intended to be demineralized and then remineralized using fluoride varnish (Proshield, president dental Germany).

The demineralizing solution and the method of induction of early artificial demineralization

The early artificial demineralization of enamel subsurface was achieved by immersing the specimens of the two groups in $20 \mathrm{ml}$ of the demineralizing solution $\left(2.2 \mathrm{Mm} \mathrm{CaCl}_{2}, 2.2 \mathrm{Mm}\right.$ $\mathrm{NaH}_{2} \mathrm{Po}_{4}, 0.05 \mathrm{M}$ Lactic acid, $0.2 \mathrm{ppm}$ Fluoride and the solution was adjusted with $50 \% \mathrm{NaOH}$ to a $\mathrm{pH}$ of 4.3$)^{(3)}$, at $37^{\circ} \mathrm{C}$ for 72 hours without stirring.

\section{The remineralizing agents}

- Fluoride varnish (Proshield, president dental Germany).

- Egg shell solution : 


\section{Production of egg shell powder :}

The egg shell powder was prepared following the world property intellectual organization protocol (WO/2004/105912 : Method of producing egg shell powder) ${ }^{(12) .}$ The contents were removed from thirty eggs, and the egg shells were cleaned with distilled water. The egg shells were then placed in a hot water bath at $100^{\circ} \mathrm{C}$ for 10 minutes after which their membranes were removed. Then the egg shells were crushed thoroughly by means of sterile mortar and pestle. Those crushed particles then heated at $1200^{\circ} \mathrm{C}$ in a muffle furnace and powdered to greatly smaller particles.

\section{Production of egg shell powder solution :}

This was preformed by dissolving one gram of egg shell powder in $20 \mathrm{ml}$ of $4 \%$ acetic acid. The clear fluid on the top was then transferred into a container $^{(3)}$. The $\mathrm{pH}$ of the solution was 11 .

\section{Method of remineralization}

By using the remineralizing agents, by immersing the teeth of one group (I) in egg shell powder solution while painting the teeth of the other group (II) with fluoride varnish, for seven consecutive days. Each day the egg shell powder solution was changed and replaced with another fresh one to enhance the process of remineralization. The remineralizing process was used in a $\mathrm{pH}$ cycling mode.

\section{The $\mathbf{p H}$ cycling mode}

The whole procedure took seven days, the idea of $\mathrm{pH}$ cycling (inducing de-and remineralization cycles) was to simulate the alternating periods of de-and remineralization that occur intra orally during the carious process. Each day of the seven days, specimens of each group were placed in the demineralizing solution for three hours (each tooth in a separate container), then they were removed from the solution and rinsed with deionized water for 5 seconds. Specimens belonging to each group were then treated with their respective remineralizing agents, group (I) was immersed in egg shell solution, specimens of group (II) were painted with fluoride varnish, and left for the rest of the day. The next day teeth were rinsed as described above before immersion in the demineralizing solution. The process was repeated for seven consecutive days. The measurements of the amount of minerals using (EDX) were preformed for all specimens after three days and finally at the end of the seven days' period.

NB : Measurements of mineral content for all specimens was performed four times :

- Before induction of the subsurface artificial demineralization (base line measurements).

- After artificial subsurface demineralization.

- After 3 days of remineralization(using pH cycling mode).

- At the end of seven days remineralization period (using $\mathrm{pH}$ cycling mode).

\section{Statistical analysis}

Numerical data were explored for normality by checking the distribution of data and using tests of normality (Kolmogorov-Smirnov and Shapiro-Wilk tests). Data were presented as mean, and, standard deviation (SD).

Repeated measures ANOVA test was used to study the changes by time. Tukey's post-hoc test was used for pair-wise comparisons when ANOVA test was significant.

Student-t-test was used to compare between the two main groups.

The significance level was set at $\mathrm{P} \leq 0.05$. Statistical analysis was performed with IBM $^{\circledR}$ SPSS $^{\circledR}$ Statistics Version 20 for Windows.

\footnotetext{
${ }^{\circledR}$ IBM Corporation, NY, USA.

${ }^{\circledR}$ SPSS, Inc., an IBM Company.
} 


\section{RESULTS}

\section{A) Calcium atomic weight $\%$}

\section{Comparison between main groups}

At base line, after demineralization as well as after 3 days from remineralization, there was no statistically significant difference between mean $\mathrm{Ca}$ atomic weight $\%$ in the two groups. While 7 days after remineralization; Group (II) showed statistically significantly higher mean $\mathrm{Ca}$ atomic weight $\%$ than Group (I)as revealed by student-t-test (table 1).

\section{Changes by time}

In Group (I); according to table (1), using one way ANOVA test there was a non statistically significant decrease in mean $\mathrm{Ca}$ atomic weight $\%$ after demineralization. Three days after remineralization; there was non- statistically significant increase in mean $\mathrm{Ca}$ atomic weight \%.There was also nonstatistically significant increase in mean $\mathrm{Ca}$ atomic weight $\%$ after 7 days compared with after 3 days. However, the mean $\mathrm{Ca}$ atomic weight $\%$ after 7 days showed non statistically significantly lower mean value compared to the mean $\mathrm{Ca}$ atomic weight $\%$ at base line.

In Group (II); there was a non statistically significant decrease in mean $\mathrm{Ca}$ atomic weight $\%$ after demineralization. Three days after remineralization; there was non- statistically significant increase in mean $\mathrm{Ca}$ atomic weight $\%$.There was a non significant increase in mean $\mathrm{Ca}$ atomic weight $\%$ after 7 days compared with after 3 days. The mean $\mathrm{Ca}$ atomic weight $\%$ after 7 days showed non-statistically significant difference from base line value.

\section{According to two way ANOVA test,}

- Regardless to the treatment stage, group (II) recorded statistically significant higher $\mathrm{Ca}$ atomic wt $\%$ than group(I).

- Irrespective of the treatment group the treatment stage affected the $\mathrm{Ca}$ atomic wt $\%$ (base line $\geq 7$ days $\geq 3$ days $>$ demineralization)

\section{B) Phosphorus atomic weight \%}

\section{Comparison between groups}

At base line, after demineralization as well as after remineralization, there was no statistically significant difference between mean $\mathrm{P}$ atomic weight $\%$ in the two groups as reveled by student-ttest (table 2).

\section{Changes by time}

In group (I) there was a non statistically significant decrease in the $\mathrm{P}$ atomic wt $\%$ after demineralization. Three days as well as seven days after remineralization there was a non statistically significant increase in the mean $\mathrm{P}$ atomic wt $\%$.

TABLE (1): The mean, standard deviation (SD) values and results of ANOVA and t-test for comparison between $\mathrm{Ca}$ atomic weight $\%$ in the two groups

\begin{tabular}{|c|c|c|c|c|c|c|}
\hline \multirow{2}{*}{ Time } & \multicolumn{2}{|c|}{ Group (I) } & \multicolumn{2}{c|}{ Group (II) } & \multicolumn{2}{c|}{ t-test } \\
\cline { 2 - 7 } & Mean & SD & Mean & SD & t-value & P-value \\
\hline Base line & 27.7 & 6.7 & 31.1 & 3.9 & 1.387 & $0.188 \mathrm{~ns}$ \\
\hline After demineralization & 20.3 & 6 & 24 & 3.6 & 1.672 & $0.109 \mathrm{~ns}$ \\
\hline 3 Days after remineralization & 22.1 & 6.9 & 26.9 & 3.3 & 1.985 & $0.063 \mathrm{~ns}$ \\
\hline 7 Days after remineralization & 23.6 & 7.2 & 29.2 & 3.5 & 2.212 & $0.038^{*}$ \\
\hline ANOVA & $\mathrm{F}$ & 2.205 & $\mathrm{~F}$ & 1.172 & & \\
\cline { 2 - 8 } & P value & $.1043 \mathrm{~ns}$ & P value & $0.4496 \mathrm{~ns}$ & & \\
\hline
\end{tabular}

*: Significant at $P \leq 0.05 \quad n s ;$ non-significant $(p>0.05)$ 
TABLE (2): The mean, standard deviation (SD) values and results of ANOVA and t-test for comparison between $\mathrm{P}$ atomic weight $\%$ in the two groups

\begin{tabular}{|c|c|c|c|c|c|c|}
\hline \multirow{2}{*}{ Time } & \multicolumn{2}{|c|}{ Group (I) } & \multicolumn{2}{c|}{ Group (II) } & \multicolumn{2}{c|}{ t-test } \\
\cline { 2 - 7 } & Mean & SD & Mean & SD & t-value & P-value \\
\hline Base line & 10.9 & 5.1 & 7.6 & 1.7 & 1.941 & 0.218 \\
\hline After demineralization & 6.5 & 3.7 & 3.8 & 1.9 & 2.053 & 0.089 \\
\hline 3 Days after remineralization & 7.3 & 4.4 & 4.4 & 1.9 & 1.913 & 0.063 \\
\hline 7 Days after remineralization & 8.7 & 5.1 & 5.1 & 2.3 & 2.035 & 0.123 \\
\hline \multirow{2}{*}{ ANOVA } & F & 1.748 & F & 7.248 & & \\
\cline { 2 - 7 } & P value & $0.1747 \mathrm{~ns}$ & P value & $0.0006^{*}$ & & \\
\hline
\end{tabular}

*: Significant at $P \leq 0.05 n s ;$ non-significant $(p>0.05)$

In group (II) there was a statistically significant decrease in the mean $\mathrm{P}$ atomic wt $\%$ after demineralization. There was a non statistically significant increase in the $\mathrm{P}$ atomic wt $\%$ after three days as well as after seven days of remineralization.

Totally regardless of the treatment stage, group (I) recorded statistically significantly higher $\mathrm{P}$ atomic wt \% than group (II), as reveled by the two way ANOVA test.

- Regardless of the treatment group there was a statistically significant difference in $\mathrm{P}$ atomic wt $\%$ between the treatment stages (baseline $>7$ days $>3$ days $>$ demineralization)

C:SharedDatal2017 1 Hala Faresl1 S-01.spc

Label:1 S

kV:30.0 Tilt:0.0 Take-off:42.5 DetTypeSDD Apollo 40 Res:130 Amp.T:6.4 FS : 17489 Lsec : 10

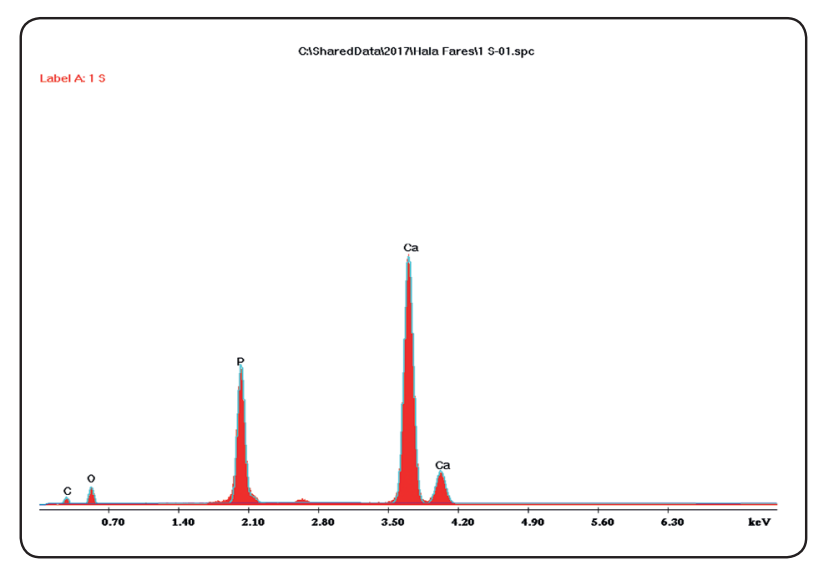

$\begin{array}{lllllll}\text { Element } & \text { Wt\% } & \text { At\% } & \text { K-Ratio } & \text { Z } & \text { A } & \text { F } \\ \text { C K } & 8.97 & 18.88 & 0.0167 & 1.0539 & 0.1769 & 1.0008 \\ \text { O K } & 21.07 & 33.30 & 0.0203 & 1.0390 & 0.0928 & 1.0002 \\ \text { P K } & 19.91 & 16.25 & 0.1501 & 0.9699 & 0.7643 & 1.0169 \\ \text { CaK } & 50.04 & 31.57 & 0.4512 & 0.9774 & 0.9226 & 1.0000 \\ \text { Total } & 100.00 & 100.00 & & & & \end{array}$

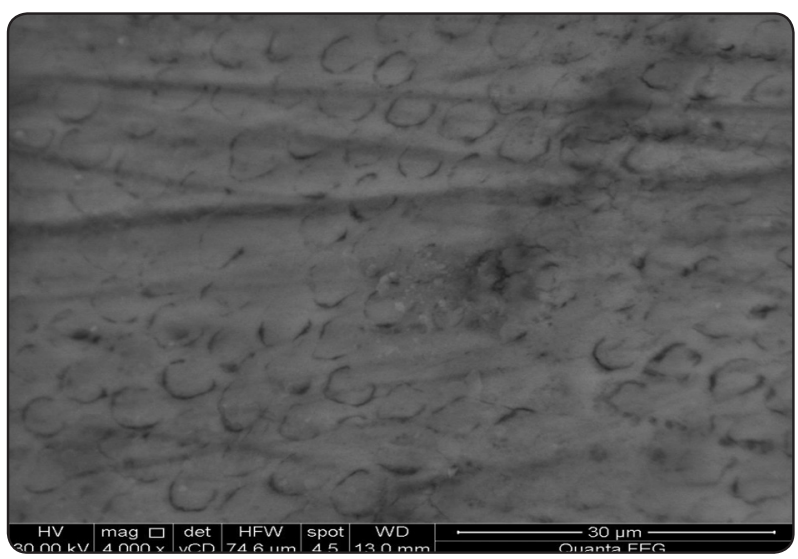

Fig. (1) (a \& b) Elemental analysis by EDX and Structural analysis by SEM of enamel surface of one specimen after seven days remineralization using egg shell powder solution. 
C: ISharedDatal2017 $\mathrm{Hala}$ Fares $\backslash 2 \mathrm{~S}-02 . \mathrm{spc}$

Label:2 S

kV:30.0 Tilt:0.0 Take-off:42.5 DetTypeSDD Apollo 40 Res:130 Amp.T:6.4 FS : 17766 Lsec : 10

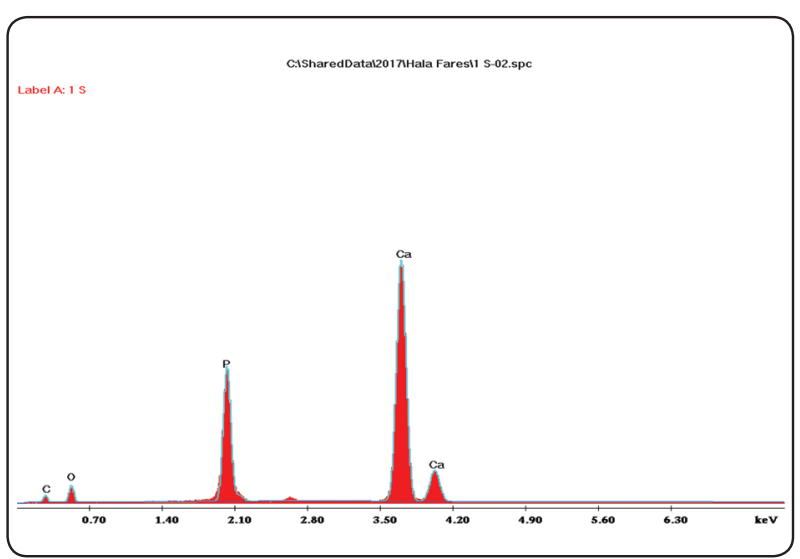

$\begin{array}{lllllll}\text { Element } & \text { Wt } \% & \text { At\% } & \text { K-Ratio } & \text { Z } & \text { A } & \text { F } \\ \text { C K } & 9.64 & 20.05 & 0.0181 & 1.0533 & 0.1784 & 1.0008 \\ \text { O K } & 21.29 & 33.26 & 0.0206 & 1.0383 & 0.0933 & 1.0002 \\ \text { P K } & 19.67 & 15.88 & 0.1484 & 0.9693 & 0.7653 & 1.0168 \\ \text { CaK } & 49.40 & 30.81 & 0.4458 & 0.9766 & 0.9240 & 1.0000 \\ \text { Total } & 100.00 & 100.00 & & & & \end{array}$

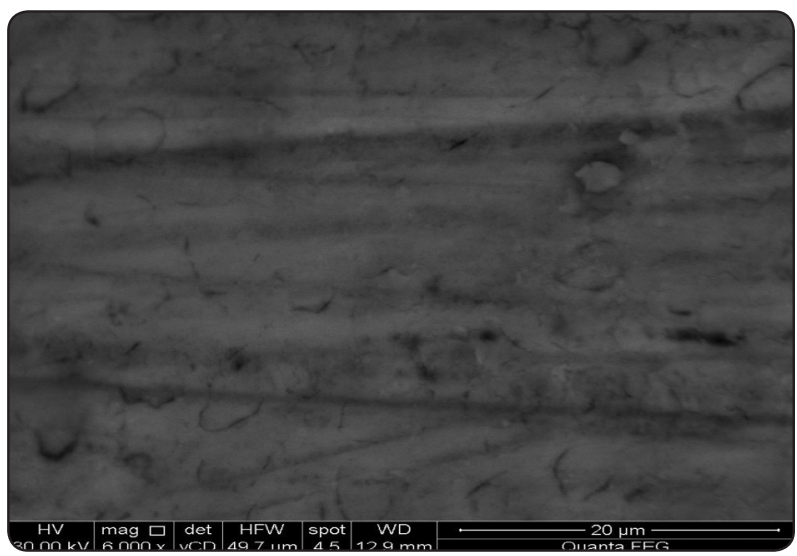

Fig. (2) (c \& d) Elemental analysis by EDX and Structural analysis by SEM of enamel surface of another specimen after seven days remineralization using egg shell powder solution.
C:ISharedDatal2017\Hala Fares 3 S-03.spc

Label:3 S

kV:30.0 Tilt:0.0 Take-off:42.5 DetTypeSDD Apollo 40 Res:130 Amp.T:6.4 FS : 16180 Lsec : 10
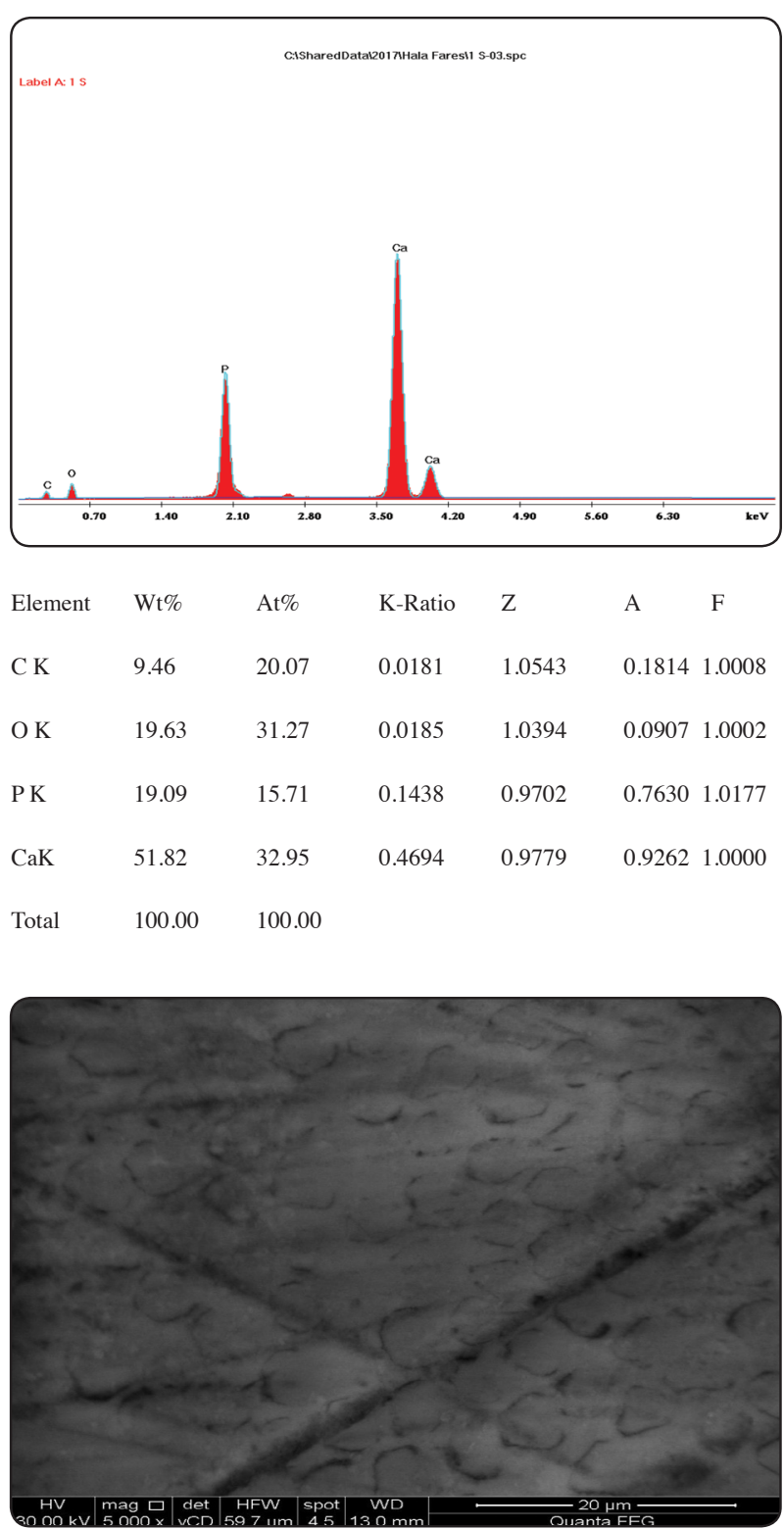

Fig. (3) (e \& f) Elemental analysis by EDX and Structural analysis by SEM of enamel surface of athird specimen after seven days remineralization using egg shell powder solution. 
C:LSharedData\2017 \Hala Fares $\backslash 1$ F-01.spc

Label:1 F

kV:30.0 Tilt:0.0 Take-off:42.2 DetTypeSDD Apollo 40 Res:136 Amp.T:12.8 FS : 7602 Lsec : 10

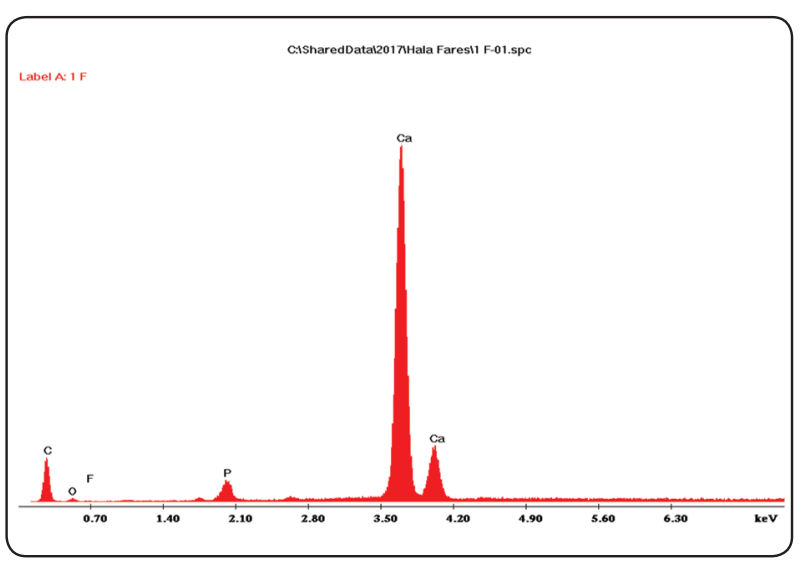

\begin{tabular}{lllllll} 
Element & Wt $\%$ & At\% & K-Ratio & Z & A & F \\
C K & 31.26 & 57.10 & 0.1218 & 1.0437 & 0.3729 & 1.0007 \\
O K & 5.35 & 7.34 & 0.0043 & 1.0290 & 0.0776 & 1.0002 \\
F K & 0.64 & 0.74 & 0.0007 & 0.9683 & 0.1102 & 1.0004 \\
P K & 2.95 & 2.09 & 0.0224 & 0.9606 & 0.7720 & 1.0264 \\
CaK & 59.80 & 32.73 & 0.5857 & 0.9672 & 1.0127 & 1.0000 \\
Total & 100.00 & 100.00 & & & & \\
\hline
\end{tabular}

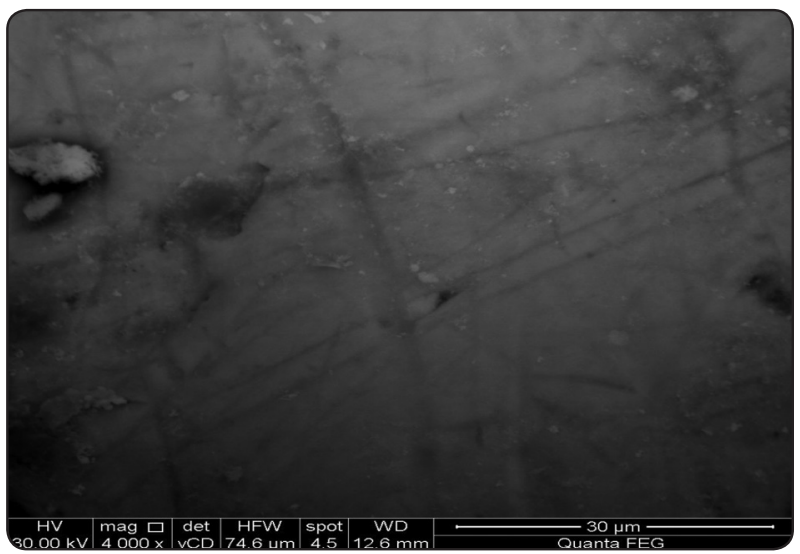

Fig. (4) ( $g$ \& h) Elemental analysis by EDX and Structural analysis by SEM of enamel surface of a specimen after seven days remineralization using fluoride varnish.
C:ISharedDataL2017\Hala Fares\2 F-02.spc

Label:2 F

kV:30.0 Tilt:0.0 Take-off:42.5 DetTypeSDD Apollo 40 Res:130 Amp.T:6.4 FS : 14949 Lsec : 10
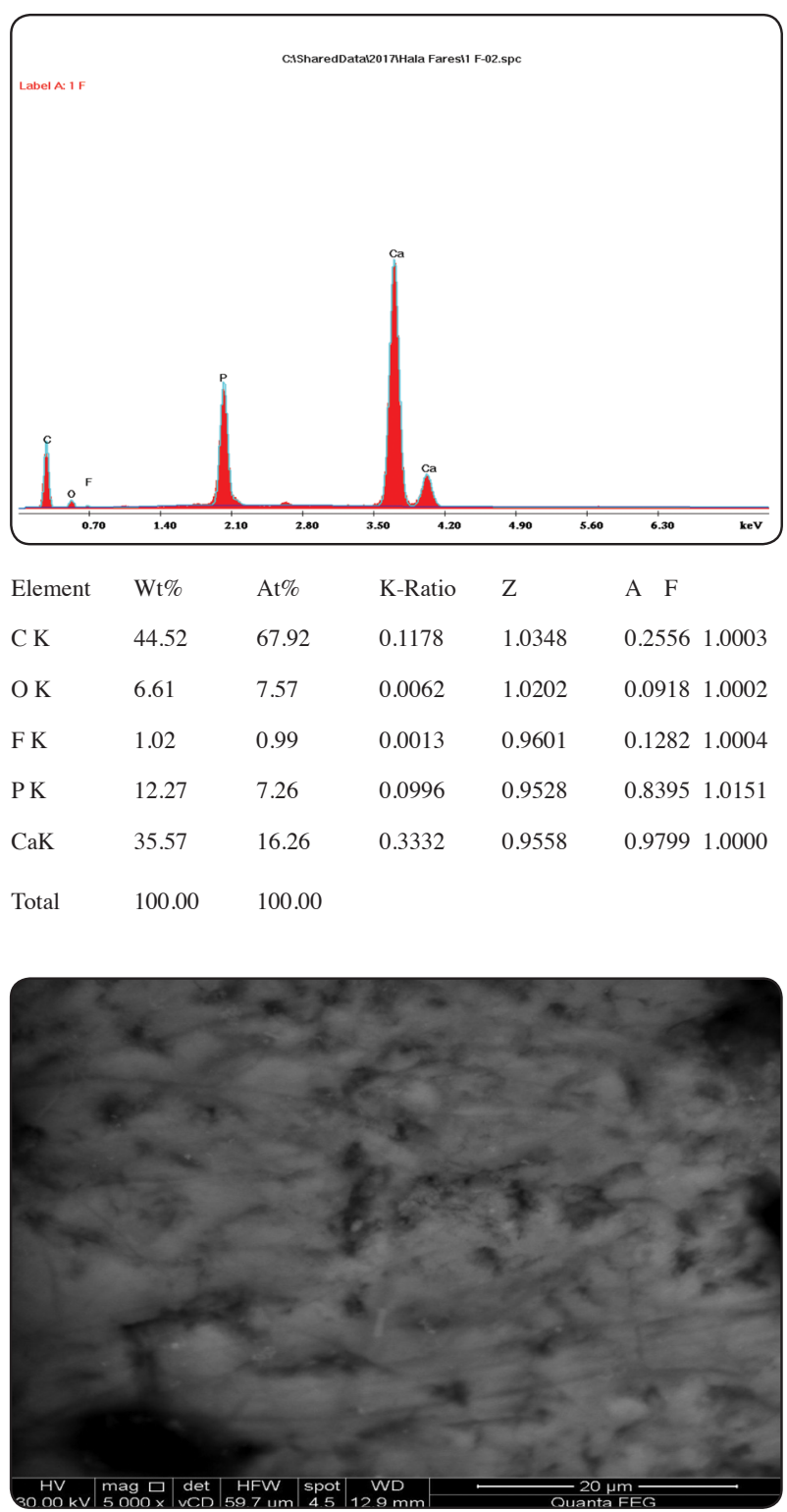

Fig. (5) (I\& J) Elemental analysis by EDX and Structural analysis by SEM of enamel surface of another specimen after seven days remineralization using fluoride varnish. 
C: SharedDatal2017 $\mathrm{Hala}$ Fares 13 F-03.spc

Label:3 F

kV:30.0 Tilt:0.0 Take-off:42.6 DetTypeSDD Apollo 40 Res:130 Amp.T:6.4 FS : 11579 Lsec : 10
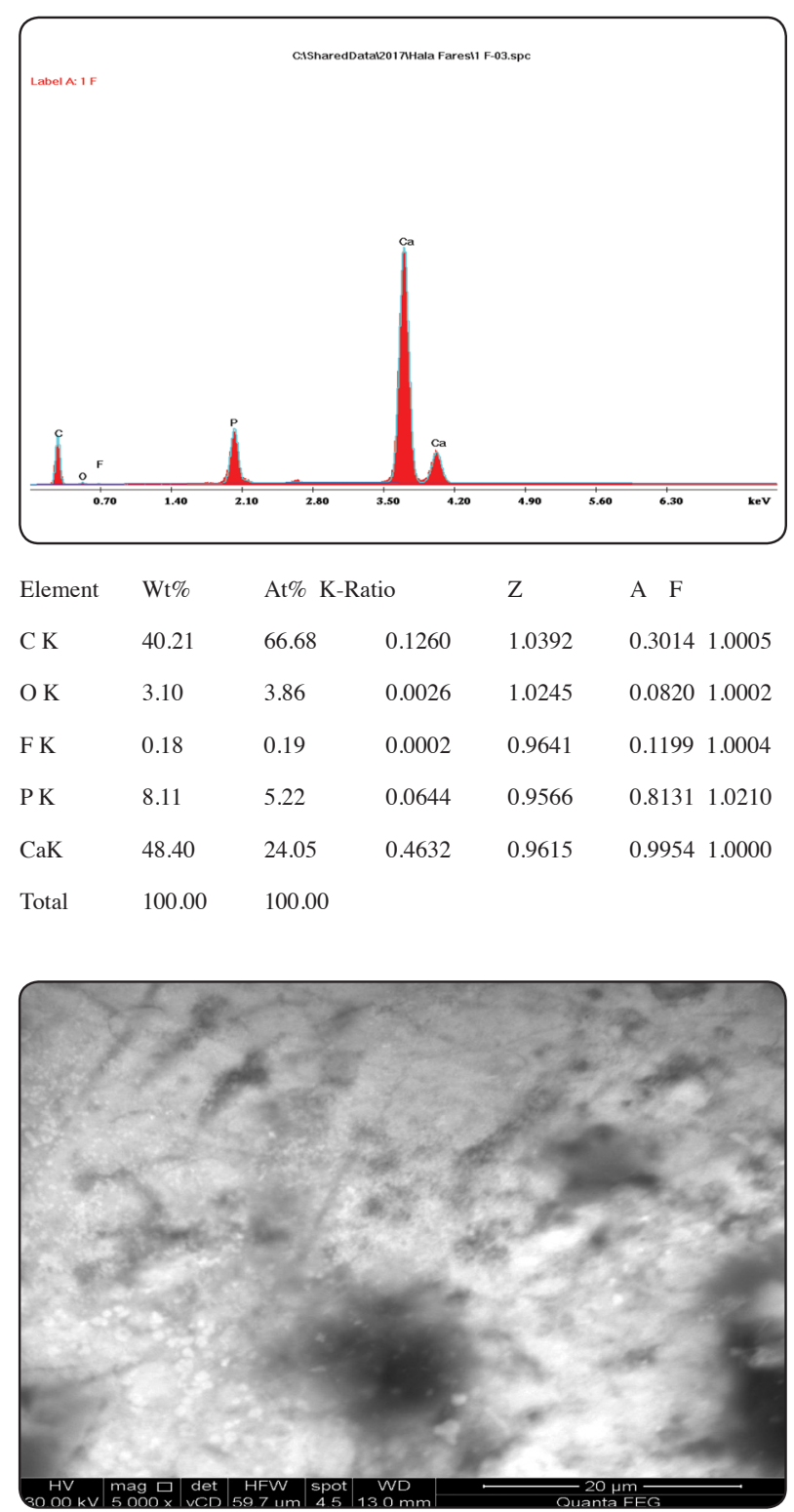

Fig. (6) (K \& L) Elemental analysis by EDX and Structural analysis by SEM of enamel surface ofa third specimen after seven days remineralization using fluoride varnish.

\section{DISCUSSION}

Incipient enamel demineralization lesions are reversible provided that a super saturated state of calcium and phosphorous ions is maintained adjacent to enamel ${ }^{(4,13)}$. This study assessed and compared the efficacy of fluoride varnish and chicken egg shell solution for remineralization of enamel simulated demineralization in permanent teeth. The efficacy of egg shell solution for remineralization of early enamel demineralization lesions was rarely previously investigated. However, the results could be anticipated because egg shell solution demonstrates a very high percentage of bioavailable calcium, phosphorous and other minerals ${ }^{(2,3)}$. Added to that when compared with other natural calcium sources, egg shell solution has low level of toxic metals like $\mathrm{Pb}, \mathrm{AL}, \mathrm{Cd}$ and $\mathrm{Hg}$. The $\mathrm{N}$-terminal sequence (Met-Ala-val-Pro-Gln-thrMet-Val-Gln) of egg shell matrix proteins has been suggested as an important factor in the increased calcium transport and considered as a potential significance of egg shell calcium when used as calcium supplements ${ }^{(14,15)}$. The acetic acid used to prepare the egg shell solution also ensured the egg shell powder was virtually free of pathogens ${ }^{(16)}$. For standardization, the teeth (specimens)were collected from the same place and belonged to a limited age range To conduct this study, in vivo it seemed difficult, if not impossible, to control all the confounding factors in clinical studies such as diet, patient cooperation, intraoral factors and interpretation of results. Therefore, in this study we used a pH cycling mode for caries simulation in vitro, in an attempt to simulate the normal intraoral conditions. Regarding the sample size calculation (power analysis), its performance depends on certain statistical measurements plus the effective size which is the difference between the groups to be compared regarding the primary outcome. Using $\alpha$ level of 0.05 and $\beta$ level of 0.20 , the minimum estimated sample size was found to be ten samples per group giving a total of twenty samples.In this 
study the results showed that when the two groups were compared (group (II) using fluoride as a remineralizing agent and group (I) using egg shell solution as a remineralizing agent), it was found that there was no statically significant difference between mean calcium atomic weight $\%$ in the two groups, at base line, after demineralization, as well as after three days of remineralization. While seven days after remineralization, group (II) showed statistically significantly higher mean calcium atomic weight $\%$ than group (I). For remineralization to effectively occur bioavailable calcium and phosphates are essential ${ }^{(17,18)}$. Therefore the rich bioavailabilty of calcium and phosphates present in egg shell solution ${ }^{(19)}$, together with its increased $\mathrm{pH}$ might be responsible for its remineralization potential. The increased $\mathrm{pH}$ of remineralizing agent was described as favorable as it increased the ion activity of anions which provided more availability of these ions for remineralization ${ }^{(3)}$. Regarding the $\mathrm{P}$ atomic wt $\%$ there was no statistically significant difference between the two tested groups. Regarding the changes by time in calcium atomic Wt $\%$ after seven days group (I) showed non statistically significantly lower mean value compared to that at base line. In group (II) also, after seven days there was no statistically significant difference from the base line value. This meant that remineralization using fluoride varnish could reach close values to the normal base line values (before induction of artificial demineralization). This was not the case for remineralization using egg shell solution i.e. there was mineral gain but not to the extent of reaching the normal base line values. Regarding the $\mathrm{P}$ atomic $\mathrm{wt} \%$, after seven days and for the two groups, there was a non statistically significant increase, yet it did not reach the normal base line values. To simulate the sub-surface demineralization lesions while maintaining the superficial enamel layer intact, weak organic acids such as lactic or acetic acid are included in the composition of the demineralizing agent $^{(20,21)}$. Furthermore, the presence of calcium and phosphate ${ }^{(22)}$, as well as fluoride ${ }^{(23)}$, in solution helped preserve the superficial enamel layer while stimulating mineral loss from the subsurface layer.

Energy dispersive x-rays analysis (EDX) has been used for elemental analysis at the ultra structural level. It is one of the most recent micro analytical techniques that are used in conjunction with scanning electron microscope (SEM), where SEM performs the structural analysis while elemental analysis is performed by $\mathrm{EDX}^{(24-26)}$. The EDX $\mathrm{x}$-ray detector measures the number of emitted $\mathrm{x}$-rays versus their energy. Spectrum of energy versus relative counts of detected x-rays is obtained and evaluated for qualitative and quantitative determination of the elements present in the specimen using a computer based program ${ }^{(25)}$.

\section{CONCLUSION}

Both remineralization agents used in this study were found to be effective in tooth healing. However, fluoride varnish was found to be comparatively more effective.

\section{RECOMMENDATION}

Further research may be needed using comparatively longer evaluation time.

\section{ACKNOWLEDGEMENTS}

We would like to deeply thank Professor Dr. Wedad Etman,Professor of Operative Dentistry, College of Oral and Dental Surgery-Tanta University, for her continued help on the subject of this study.

\section{REFERENCES}

1. SelwitzRH,Ismali AL \& Pitts NB. Dental caries. Lancet 2007;369:51-59

2. HaghgooR,Mehran M, Ahmad Vand M \& Ahmad MJ. Remineralization of egg shell versus nano-hydroxyapatite on caries-like lesions is permanent teeth (in vitro). J Int Oral Health 2016;8:435-439 
3. Monyb, Ebenezar AVR, Ghani MF, Narayanan A, Anand s \& Mohan AG. Effect of chicken egg shell powder solution on early enamel carious lesions : An unvitro preliminary study. J ClinDiagn Res 2015;9:Zc30-zc32

4. Pearce EL \& Moore AJ.Remineralization of softened bovine enamel following treatment of overlying plaque with a mineral-enriching solution.J Dent Res 1985;64:416-421

5. LataS, Varghese No \&Varughese JM. Remineralization potential of fluoride and amorphous calcium phosphatecasein phosphor peptide on enamel lesions: An in vitro comparative evaluation. J conserv Dent 2010;13:42-46.

6. Murray JJ, Rugg-Gunn AJ\&Jenkies GN. Fluoride in caries

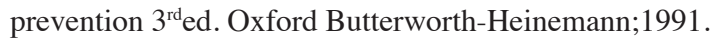

7. StadelmanwJ. Eggs and egg products.In:francis FJ, editor. Encyclo-Pedia of food science and technology. $2^{\text {nd }} e d$. Newyork:John,Wiley and Sons 2000;593-599

8. Kattimani VS, Chakravathi PS, Kanumuru NR, Subbararo VV, Sidhathan A, Kumar TS \&etal. Eggshell derived hydroxyapatite as bone graft substitute in the healing of maxillary cystic bone defects: A preliminary report. J Int Oral Health 2014;6:15-19

9. Dupoirieux L, Pourquier D \& Souyris F. Powdered eggshell: A pilot study on a new bone substitute for use in maxillofacial surgery. J CraniomaxillofacSurg 1995;23:187-194

10. Schaafsma A, Van Doormaal JJ, Muskiet FA, Hofstede GJ, Pakan I \& Van der Veer E. Positive effects of a chicken eggshell powder-enriched vitamin-mineral supplement on femoral neck bone mineral density in health late postmenopausal Dutch women. BR J Nutr. 2002;87:267-275

11. Rovensky J, Stancikova M, Masaryk P, Svik K \&Istok R. Egg shell calcium in the prevention and treatment of osteoporosis. Int J ClinPharmacolRes 2003;23:83-92

12. Methods of producing egg shell powder: Patents: US 20060062857 A 1.

13. Silverstone LM. Remineralization phenomena. Caries Res 1977;11 Suppl 1:59-84

14. SchaasmaA\&Pakan I. Short-term effects of a chicken egg shell powder enriched dairy-based products on bone mineral density in persons with osteoporosis or osteopenia. BratislLekListy. 1999;100:651-656

15. SchaasmaA\&Pakan I. Effect of a chicken egg shell powder enriched dairy product on bone mineral density in persons with osteoporosis or osteopenia. Nutrition. 1999;15:157.
16. Shen P, anton DJ, Cochrane NJ, Walker GD, Yuan Y, Reynolds $\mathrm{C} \&$ et al. effect of added calcium phosphate on enamel remineralization by fluoride in a randomized controlled in situ trial. J Dent. 2011;39:518-525

17. Hicks J, Garcia-Godoy F \&Flatiz C. Biological factors in dental caries enamel structure and the caries process in the dynamic process of demineralization and remineralization (part 2) J ClinPediatr Dent. 2004;28:119-124

18. Gonzalez-Cabezas C. The chemistry of caries: remineralization and demineralization events with direct clinical relevance. Dent Clin North Am. 2010;54:469-478

19. Cochrane NJ \& Reynolds EC. Calcium phosphpeptides mechanisms of action and evidence for clinical efficacy. Adv Dent Res. 2012;24:41-47

20. Featherstone JD. Modeling the caries inhibitory egects of dental materials. Dent Mater 1996;12:194-197

21. Magalhaes AC, Moron BM, Comar LP, Wiegand A, Buchalla W \&Buzalaf MA. Comparison of cross sectional, hardness and transverse microradiography of artificial carious enamel lesions induced by digerent demineralizing solutions and gel. Caries Res 2009;43:474-483

22. De Groot JF, Borggreven JM \&Driessens FC. Some aspects of artificial caries lesion formation of human dental enamel in vitro. J Bio Buccale 1986;14:125-131

23. Theuns HM, van Dijk JW, Driessens FC \&Groeneveld A. The influence of the composition of demineralizing burgers on the surface layers of artificial carious lesions. Caries Res 1984;18:509-518.

24. Hegde MN,DevadigceD\&Jemsily PA. Comparative evaluation of effect of acidic heverages on enamel surface pretreated with various remineralizationagents: An in vitro study. J Conserv Dent 2012;15:351-356

25. Hegde MN, Shetty S \&Pardal D. Remineralization of enamel sub-surface lesion using casein PhosphopeptideAmorphus Calcium phosphate (CPP-ACP) J Conserv Dent. 2007;10:19-25

26. Arends J, Bosch JJ. Demineralization and re-mineralization evalustion techniques. J Dent Res. 1992;71(special issue):924-928 